\title{
Estudo anatômico das espécies de cerrado Anemopaegma arvense (Vell.) Stellf. ex de Souza (catuaba), Zeyheria montana Mart. (bolsa- de-pastor) e Jacaranda decurrens Chamisso (caroba) - Bignoniaceae
}

\author{
Claudia Mauro ${ }^{\text {*, }}$ Ana Maria Soares Pereira², Celi de Paula Silva ${ }^{1}$, Juliana Missima1, \\ Thiana Ohnuki ${ }^{1}$, Renata Benatti Rinaldi ${ }^{1}$
}

${ }^{1}$ Faculdade de Ciências Farmacêuticas e Bioquímicas, Faculdades Oswaldo Cruz, Rua Brigadeiro Galvão, 540, Barra Funda, 01151-000, São Paulo, SP, Brasil,

${ }^{2}$ Unidade de Biotecnologia Vegetal, Universidade de Ribeirão Preto, Rua Costábile Romano, 2201, Ribeirânia, 14096-380, Ribeirão Preto, SP, Brasil

\begin{abstract}
RESUMO: Foi realizado um estudo anatômico de três espécies medicinais da família Bignoniaceae, típicas de cerrado, em risco de extinção, a saber: Anemopaegma arvense, Jacaranda decurrens e Zeyheria montana, provenientes de Botucatu. Para isto, realizaram-se cortes transversais de caule, limbo e pecíolo e paradérmicos de limbo. Os cortes, corados diferencialmente com azul de alcian e fucsina básica, foram objeto de estudo e descrição anatômica. As três espécies mostram adaptações anatômicas a ambiente xerofítico, representadas por mesofilo foliar compactado, cutícula espessa (Anemopaegma e Jacaranda) e abundante aquisição de tricomas tectores (Zeyheria).
\end{abstract}

Unitermos: Anemopaegma arvense, Jacaranda decurrens, Zeyheria montana, Bignoniaceae, cerrado, xeromorfismo.

\begin{abstract}
Anatomical study of species from savanna-like formation, Anemopaegma arvense (Vell.) Stellf. ex de Souza (catuaba), Zeyheria montana Mart. (bolsa-de-pastor) and Jacaranda decurrens Chamisso (caroba) - Bignoniaceae”. The anatomy of three medicinal species belonging to the Bignoniaceae family, from savanna-like formation and in risk of extinction, was studied. They were: Anemopaegma arvense, Jacaranda decurrens and Zeyheria montana, from Botucatu. Hand-made transversal sections of stem, foliar leaf and petiole and paradermal sections of foliar leaf, differentially stained with alcian blue and basic fuchsin, were studied and described anatomically. The three species show anatomical adaptations to xerophytic environment, expressed by compaction of foliar mesophyll, thickened cuticle (Anemopaegma and Jacaranda) and acquisition of abundant non-glandular trichomes (Zeyheria).
\end{abstract}

Keywords: Anemopaegma arvense, Jacaranda decurrens, Zeyheria montana, Bignoniaceae, savanna-like vegetation, xeromorphism.

\section{INTRODUÇÃO}

O cerrado é um complexo de formações oreádicas, que vai desde o campo limpo até o cerrado, sendo que suas formas savânicas (campo sujo, campo cerrado e cerrado sensu strictu) representam ecótonos de vegetação, entre duas fisionomias extremas: a florestal, representada pelo cerradão e a campestre, constituída pelo campo limpo (Coutinho, 1978).

No estado de São Paulo, o cerrado ocorre principalmente na região centronorte, interrompido por outras formações vegetais, como nas proximidades de Ribeirão Preto, Franca e Altinópolis (Toledo Filho, 1984).

O cerrado recobria, originalmente, cerca de $14 \%$ do território paulista (Serra Filho et al., 1974) e se restringe atualmente a $1,17 \%$ do original, estando concentrado principalmente no interior do Estado, distribuído de forma fragmentada e convivendo com uma paisagem bastante modificada pela ação humana (Feldmann, 1997).

Há uma necessidade premente de preservação da riqueza faunística e florística do cerrado, que, em sua biodiversidade, pode ser comparado ao bioma Amazônia (Feldmann, 1997), estimando-se que a riqueza da flora possa alcançar entre 4 e 10 mil espécies vasculares, valores estes superiores aos encontrados em grande parte de outras floras mundiais (WWF-PRO-CER, 1995). O cerrado é atualmente um dos biomas brasileiros mais ameaçados, pois constitui a principal fronteira agropecuária do país, o que tem causado um aumento da pressão antrópica sobre a vegetação nativa (Martins et al., 1996). O ritmo veloz, intenso e desordenado de ocupação também tem pressionado este ecossistema resultando, inevitavelmente, na redução de sua biodiversidade. 
No presente estudo, foram escolhidas plantas da família Bignoniaceae, coletadas no cerrado de Botucatu, S.P. que constam entre as espécies em risco de extinção. A família Bignoniaceae é formada por tubifloras da subordem das solaníneas, que compreende cerca de 500 espécies, distribuídas nas regiões tropicais, principalmente nas Américas. São plantas lenhosas, arbustivas, algumas trepadeiras, com folhas compostas, opostas, flores diclamídeas, hermafroditas, pentâmeras, zigomorfas, reunidas em inflorescências racemosas ou cimosas. A corola é ligeiramente bilabiada. $\mathrm{O}$ androceu possui 4 estames didínamos e 1 estaminódio glandular (Jacaranda). O ovário é súpero, bicarpelar, bilocular; o fruto é seco, capsular, loculicida ou septicida, com sementes aladas (Joly, 1979).

As espécies Jacaranda decurrens, caroba, Anemopaegma arvense, catuaba ou verga-tesa e Zeyheria montana, conhecida como bolsa-de-pastor, são plantas medicinais do cerrado que apresentam, respectivamente, atividade estimulante do sistema nervoso, atividade antiinflamatória e antineoplásica sendo esta última atribuída a triterpenos, principalmente ao ácido ursólico, com baixa toxicidade em humanos (Varanda et al., 1992; Santana et al., 1980). Trabalhos recentes constataram a presença de lapachol em Zeyheria montana (Almeida et al., 1990; Jacome et al., 2001). A catuaba, Anemopaegma arvense, consta da $1^{\text {a }}$ edição da Farmacopéia Brasileira (Silva, 1929). A Anemopaegma arvense, Bignoniaceae, é confundida com outra espécie, a Erythroxylon catuaba, Eritroxylaceae, que possui o mesmo nome vulgar e é utilizada popularmente, no Brasil, para fins semelhantes. Estudos anatomo-morfológicos são particularmente úteis, neste processo de preservação, porque fornecem subsídios importantes, principalmente quando associados à farmacognosia e taxonomia na caracterização de espécies de importância.

O objetivo do presente trabalho foi a caracterização anatômica dos órgãos vegetativos destas espécies, justificada pelo fato de serem espécies com histórico de utilização popular, no Brasil, como fitoterápico e por sua elevada vulnerabilidade à extinção.

\section{MATERIAL E MÉTODOS}

O material foi coletado na região de cerrado de Botucatu, S.P., e identificado pelo Prof. Dr. Lin Chau Ming, da Faculdade de Ciências Agronômicas Lageado, UNESP Botucatu. Exsicatas destas espécies encontram-se depositadas no herbário da UNAERP, sendo seus números voucher de identificação: Jacaranda decurrens HPMU 507, Anemopaegma arvense HPMU 692, Zeyheria montana HPMU 249. Para a fixação, utilizou-se F.A.A. (formaldeído $37 \%$ (v/v): ácido acético glacial: etanol 70\%(v/v); 2:1:1), sendo após armazenado em etanol 70\%(v/v). Para a descrição histológica, foram feitos cortes a mão livre, utilizando lâmina de barbear. O material foi clarificado em solução de hipoclorito de sódio $70 \%$ (v/v) e submetido a coloração diferencial com azul de alcian $1 \%(\mathrm{p} / \mathrm{v})$ e fucsina básica $1 \%(\mathrm{p} / \mathrm{v})$. Cortes transversais e paradérmicos de limbo foliar e transversais de limbo, pecíolo e caule, foram montados em preparações semi-permanentes, em glicerina $50 \%$ (v/ v), com gotas de formalina e analisados em microscópio óptico binocular Coleman. As fotografias foram obtidas através de fotomicroscópio Karl Zeiss Jena, Jenamed 2 Histology.

\section{RESULTADOS}

\section{Anemopaegma arvense (Vell.) Stellf. ex de Souza (catuaba, catuíba ou verga-tesa). Sinonímia científica: Anemopaegma mirandum (Cham.) DC.}

É um arbusto vivaz, perene, pouco ramificado, com folhas compostas trifolioladas. Foram estudados o limbo foliar do folíolo e o caule aéreo.

\section{Descrição anatômica do limbo foliar do folíolo}

O limbo foliar apresenta uma nervura central pronunciada, com um limbo de margem revoluta (Figura 1). A epiderme unisseriada é constituída de células tabulares, distintamente maiores na face adaxial, em relação à face abaxial. A cutícula lisa é bastante espessa, bem como as paredes tangenciais da epiderme (Figura 3). Na nervura central há 3-4 camadas de colênquima angular, com raros idioblastos contendo cristais prismáticos. O feixe colateral da nervura central de morfologia em ferradura, apresenta discreto desenvolvimento secundário (Figura 2), com elementos de xilema circundados por raios parenquimáticos e elementos de tubo crivado, com células companheiras, no floema. O mesofilo foliar dorsiventral apresenta 1-2 camadas de parênquima paliçádico e 5-6 de parênquima lacunoso (Figura 2). Os estômatos da face dorsal, localizados na região da nervura, são anomocíticos (Figura 4). Foram visualizados tricomas glandulares com uma célula basal e um pedicelo unisseriado unicelular e uma glândula com 8-10 células secretoras (Figuras 3 e 4).

\section{Descrição anatômica do caule}

No caule, foi observado um início de desenvolvimento vascular secundário (Figura 5), porém não foi visualizado felogênio (Figura 6). A região cortical caulinar apresenta colênquima angular e parênquima com meatos (Figura 6). Constatou-se um xilema secundário, formado por poucos elementos de vaso, circundados por abundantes fibras esclerenquimáticas (Figura 6) Grupos de fibras de esclerênquima foram observadas, logo embaixo da região cortical caulinar, na estrutura secundária.

2. Zeyheria montana Mart. (bolsa - de - pastor). Sinonímia científica: Zeyheria digitalis (Vell.) Hoehne 
É um arbusto com folhas opostas, digitadas, pecioladas, com 4-5 folíolos. Foram estudados o limbo foliar do folíolo, o pecíolo e o caule.

\section{Descrição anatômica do folíolo}

A superfície dorsal do folíolo apresenta grande quantidade de tricomas tectores (Figuras 7 e 8). Os mesmos tricomas tectores vistos no limbo são abundantes também no pecíolo (Figura 11). Limbo, pecíolo e caule apresentam numerosos tricomas glandulares pedicelados, com pedicelo unisseriado pluricelular e raros tricomas glandulares com pedicelo unicelular e glândula constituída por 4 células secretoras (Figura 9). O limbo foliar apresenta uma nervura central muito desenvolvida, saliente, com a epiderme recoberta por cutícula espessa, esculturada, com reentrâncias e saliências regulares, restrita à face ventral da epiderme (Figuras 7 e 8). Na região da nervura central, há colênquima angular. $\mathrm{O}$ desenvolvimento vascular secundário está bastante pronunciado (Figura 7). O mesofilo foliar dorsiventral apresenta uma única camada de parênquima paliçádico e 1-2 de lacunoso (Figura 8).

\section{Descrição anatômica do pecíolo}

O pecíolo apresenta um discreto crescimento secundário, formando uma estrutura vascular de morfologia estrelada (Figura 10). Foram observados tricomas tectores estrelados no ápice (Figura 11).

\section{Descrição anatômica do caule}

No caule há um córtex constituído por colênquima angular e parênquima homogêneo, com meatos, com um sistema vascular secundário em início de desenvolvimento. A epiderme está presente, recoberta de tricomas tectores semelhantes aos observados no limbo foliar do folíolo (Figura 12).

\section{Jacaranda decurrens Chamisso (caroba, carobinha- do-campo)}

É um arbusto campestre, com folhas compostas bipinadas, curto-pecioladas, com foliólulos paripenados. Foram estudados o foliólulo, o pecíolo e o caule aéreo.

\section{Descrição anatômica do limbo foliar do foliólulo}

O limbo foliar apresenta nervura central bem desenvolvida, com margem revoluta. Na nervura central, há um feixe colateral fechado, circundado por abundantes fibras esclerenquimáticas, formando uma calota, composta de várias camadas (Figuras 13 e 15). O foliólulo apresenta epiderme unisserriada e tricomas tectores na face ventral (Figura 14). O mesofilo foliar dorsiventral apresenta 1-2 camadas de parênquima paliçádico e 2-3 de lacunoso (Figuras 14 e 15). As células epidérmicas fundamentais, em torno das células anexas ou subsidiárias dos numerosos estômatos, apresentam um aspecto plicado (Figura 16), estando situadas abaixo das células fundamentais epidérmicas. Ainda em corte paradérmico, foram visualizados idioblastos com cristais prismáticos (Figura 20).

\section{Descrição anatômica do pecíolo}

O pecíolo apresenta um desenvolvimento vascular secundário, com uma calota compacta formada por fibras do floema primário e duas concrescências laterais, com feixes vasculares em seu interior (Figura 17). Foram visualizados estômatos com células guarda localizadas acima das células epidérmicas (Figura 18).

\section{Descrição anatômica do caule}

O caule apresenta epiderme unisseriada, recoberta por uma cutícula espessa; foi visualizado estômato com câmaras sub-estomáticas localizadas ligeiramente acima da epiderme (Figura 19). A região cortical caulinar apresenta 1-2 camadas de colênquima angular, seguidas de 2 camadas de parênquima. $\mathrm{O}$ xilema secundário apresenta poucos elementos de vaso e abundantes fibras esclerenquimáticas (Figura 19).

\section{DISCUSSÃO}

As 3 espécies analisadas mostram adaptações a ambiente xerofítico, com compactação dos parênquimas clorofilianos do mesofilo foliar (Jacaranda decurrens e Anemopaegma arvense) e abundantes tricomas tectores na face dorsal do limbo foliar (Zeyheria montana). Observou-se, nas três espécies analisadas, um espessamento da cutícula e das paredes tangenciais da epiderme. Os mesofilos foliares dorsiventrais apresentam pequena proporção de parênquima clorofiliano, refletindo, a nível histológico, a redução do limbo foliar, compatível com adaptações a ambiente árido. A ocorrência de mesofilo dorsiventral é característico de adaptação a ambiente xerofítico (Fahn, 1990). Pimenta et al. (1996) constataram, em Jacaranda puberula, que situações climáticas afetam a morfoanatomia dos órgãos vegetais.

Os mesofilos dorsiventrais dos folíolos e foliólulos das três espécies analisadas se caracterizam por apresentar pequena quantidade de parênquima paliçádico, que se restringe a 1-2 camadas, apenas. Em Jacaranda decurrens, os diminutos estômatos epidérmicos do limbo foliar, em vista paradérmica, estão situados abaixo das células fundamentais da epiderme.

De maneira geral, é rara a ocorrência de desenvolvimento secundário em folhas (Fahn, 1990). Na nervura central do limbo foliar de Zeyheria montana, este desenvolvimento é muito pronunciado, formando 
um sistema vascular do tipo solenostelo ou sifonostélica contínua anfiflóica, com várias calotas de floema secundário.

Hyakutake \& Grotta (1965) constataram a presença de periderme em caule de A. arvense. Não foi visualizada periderme ou mesmo felogênio em formação, nos caules das 3 espécies estudadas, talvez pelo fato do material estudado ser proveniente de órgãos vegetais ainda jovens. Observou-se, porém, um desenvolvimento vascular secundário caulinar, nas 3 espécies estudadas, bem como o desenvolvimento secundário observado na nervura central dos folíolos de Zeyheria montana.

Anemopaegma arvense foi estudada anatomicamente por Morretes (1980), Silva (1929), Hyakutake \& Grotta (1965) e Jorge et al. (1989). Hyakutake \& Grotta (1965) interpretaram a existência de fibras esclerenquimáticas, formando calotas, como um periciclo fibroso. Jorge et al. (1989), cita Morretes, que discorda desta interpretação, referindo-se a estas fibras apenas como esclerênquima. Concordamos com Morretes (1980), no que diz respeito à origem das calotas de fibras esclerenquimáticas, logo abaixo da região cortical caulinar.

Calotas similares de fibras de esclerênquima foram encontradas também no limbo foliar de Jacaranda decurrens, tanto na nervura central quanto nas secundárias, localizadas no mesofilo foliar. Esclerênquima abundante é muitas vezes encontrado em vegetação xeromorfa, de acordo com Esaú (Esaú, 1974) e Fahn (Fahn, 1990), o que explicaria sua constatação no limbo foliar do foliólulo de Jacaranda decurrens e em caule de Anemopaegma arvense.

Contribuições anatômicas para o estudo de Anemopaegma arvense são necessárias, se se considerar que, além da confusão causada pela ocorrência de plantas pertencentes a distintas famílias botânicas, com o mesmo nome vulgar, catuaba, existem, ainda, 4 variedades taxonômicas já descritas, da espécie arvense (Ferreira, 1973).

\section{AGRADECIMENTOS}

Às Faculdades Oswaldo Cruz, pelo respaldo financeiro e pela bolsa concedida às estagiárias do Projeto Farmácia Viva.

\section{REFERÊNCIAS}

Almeida ER, Silva-Filho AAA, Santos ER, Lopes CA 1990. Antiinflamatory action of lapachol. J Ethnopharmacol 29: 239-241.

Coutinho LM 1978. O conceito de cerrado. Rev Bras Bot 1: 17-23.

Esaú K 1974. Anatomia de Plantas com Sementes. Editora Edgard Blucher.

Fahn A 1990. Plant Anatomy $4^{\text {th }}$ edition, Pergamon Press.

Feldmann F 1997. Prefácio. In: São Paulo (Estado). Secretaria do Meio Ambiente. Cerrado: Bases para Conservação e Uso Sustentável das Áreas de Cerrado do Estado de São Paulo. São Paulo: SMA.

Ferreira MB 1973. Bignoniaceae do Distrito Federal - I. O gênero Anemopaegma Mart. Oréades. Depto de Botânica do ICB, UFMG, Belo Horizonte.

Hyakutake S, Grotta AS 1965. Contribuição ao estudo morfológico e anatômico de Anemopaegma arvense (Vell.) Stellfeld var. petiolata Bignoniaceae. Rev Fac Farm Bioquim São Paulo 3: 51-78.

Jacome RLRP, Raslan DS, Wagner H, Oliveira AB 2001. Estudo químico de Zeyheria montana M. (bolsa-de-pastor). Rev Bras Farmacogn 11: 5-12.

Joly AB 1979. Botânica: Introdução à Taxonomia Vegetal. $5^{a}$ ed., São Paulo, Edit. Nacional.

Jorge LIF, Ferro VO, Sakuma AM 1989. Determinação das principais características estruturais e químicas da droga Anemopaegma (Vell.) Stellfeld. Revista do Instituto Adolfo Lutz 49: 183-191.

Martins CR, Carmona R, Leite L 1996. Fenologia e qualidade de sementes de Gymnopogon doellii - uma gramínea ameaçada de extinção. In: Contribuição ao Conhecimento Ecológico do Cerrado, Brasília, UnB, p. 71-74.

Morretes BL 1980. Contribuição ao Conhecimento da Anatomia Ecológica de Plantas do Cerrado de EMAS-SP e da Caatinga Amazônica do Km. 62 da Rodovia BR 174. Tese de Livre Docência, Instituto de Biociências, USP apud Revista do Instituto Adolfo Lutz 49: 183-191, 1989.

Pimenta JA, Medri ME, Bianchini E, Muller C, Okamoto JM, Francisconi LMJ, Correa GT 1996. Aspectos da morfoanatomia e fisiologia de Jacaranda puberula Cham. (Bignoniaceae) em condições de hipoxia. Rev Bras Bot 19: 214-220.

Santana CF, Lins LJP, Asfora JJ, Melo M, Lima OG, d'Albuquerque IL 1980. Revista do Instituto de Antibiótico 20: 61-62.

Serra Filho R, Cavalcante AC, Guillaumon JR, Chiarini JV, Nogueira FP, Ivancko CM, Barbieri JL, Donzelli PL, Coelho AGS, Bittencourt I 1974. Levantamento de cobertura natural e de reflorestamento no cerrado de São Paulo. Boletim Técnico I.F., São Paulo, p. 1-56.

Silva RAD 1929. Farmacopéia Brasileira. São Paulo, Companhia Editora Nacional, p. 194 e 385.

Toledo Filho DV 1980. Composição Florística e Estrutura Fitossociológica de Vegetação de Cerrado no Município de Luis Antônio, S.P. Dissertação de mestrado, Universidade Estadual de Campinas, Campinas.

Varanda EM, Zuniga GE, Salatino A, Roque NF, Corcuera LJ 1992. Effect of ursolic acid from epicuticular waxes of Jacaranda decurrens on Schizaphis graminum. J Nat Prod 55: 800-803.

WWF-PRO-CER 1995. De grão em grão, o cerrado perde espaço. Cerrado-Impactos do processo de ocupação. Brasília, WWF-Fundo Mundial para a Natureza. 

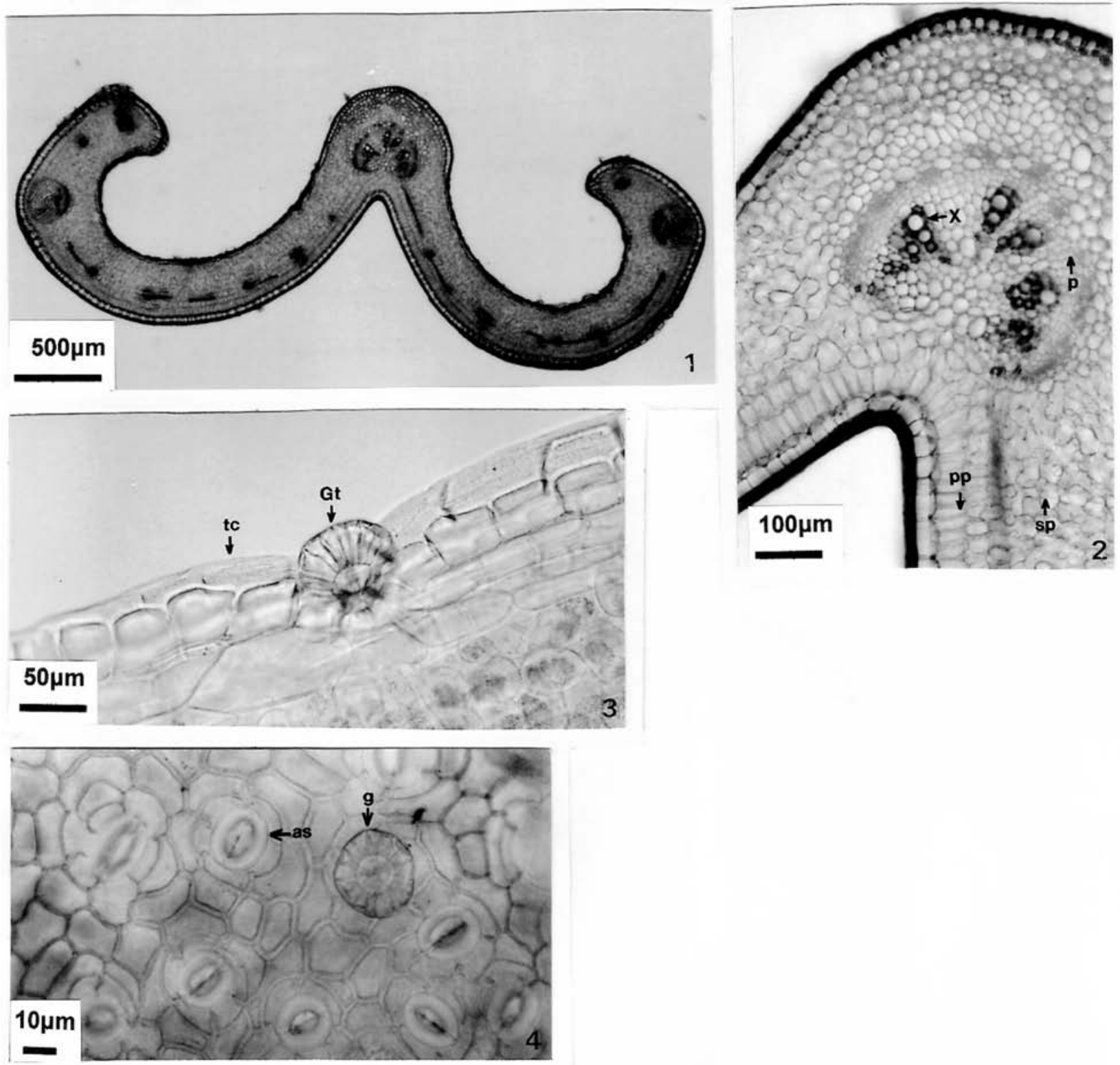

Figuras 1 a 4. Aspectos anatômicos de Anemopaegma arvense (Vell.) Stellf. Ex de Souza: 1. Corte transversal do limbo (visão geral). 2. Corte transversal do limbo: nervura central $(x=$ xilema; $p=$ floema; $p p=$ parênquima paliçádico; $s p=$ parênquima lacuosos). 3. Corte paradérmico do limbo (tc = cutícula espessada; $\mathrm{Gt}=$ tricoma glandular). 4. Corte paradérmico do limbo (as = estômato anomocítico; $\mathrm{g}$ = tricoma glandular - visto de cima). 

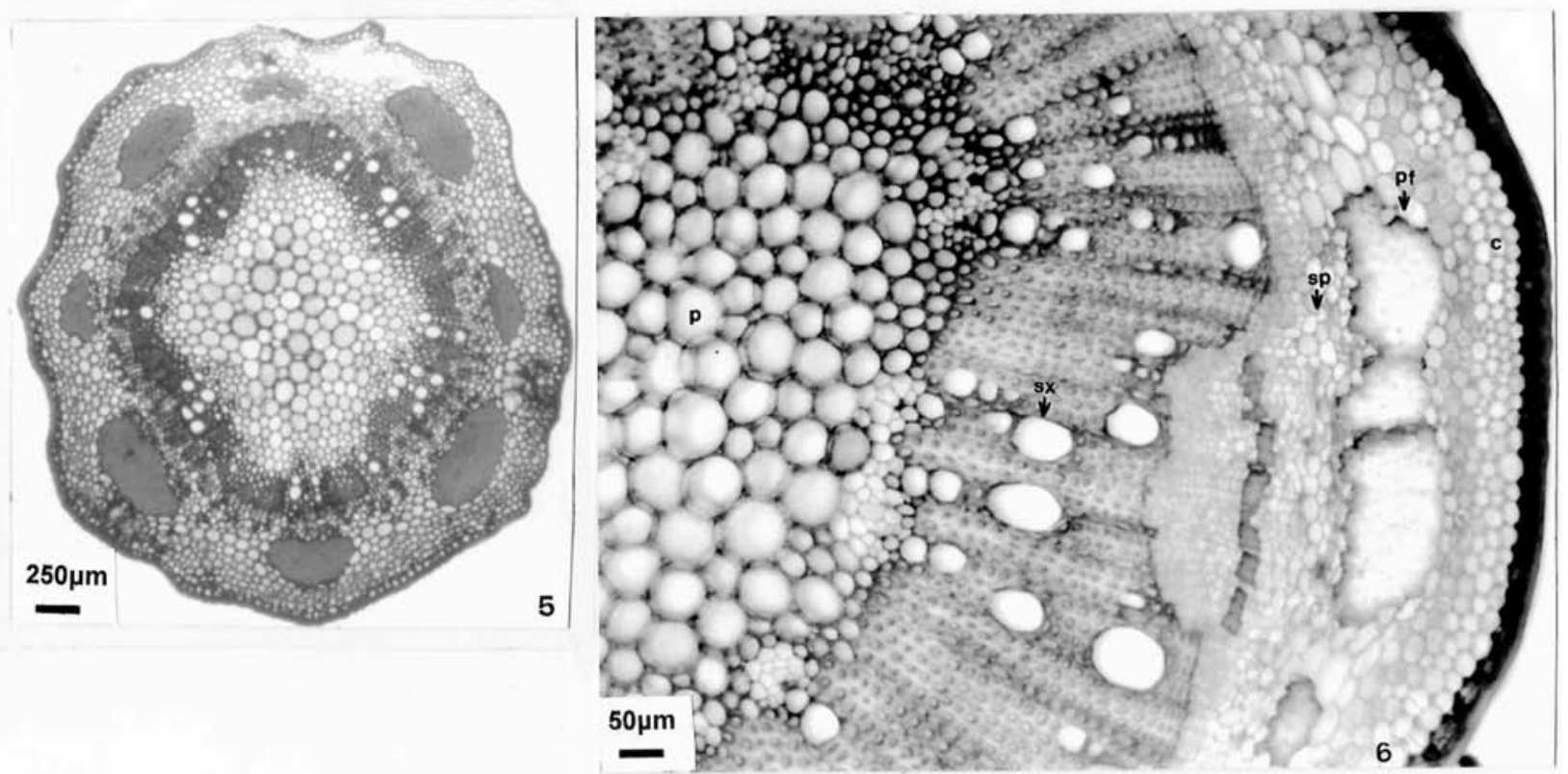

Figuras 5 e 6. Aspectos anatômicos de Anemopaegma arvense (Vell.) Stellf. Ex de Souza: 5. Corte transversal do caule (visão geral). 6. Corte transversal do caule: $(c=$ colênquima; $p f=$ fibras do floema primário; $s x=$ xilema secundário; $p=$ medula).

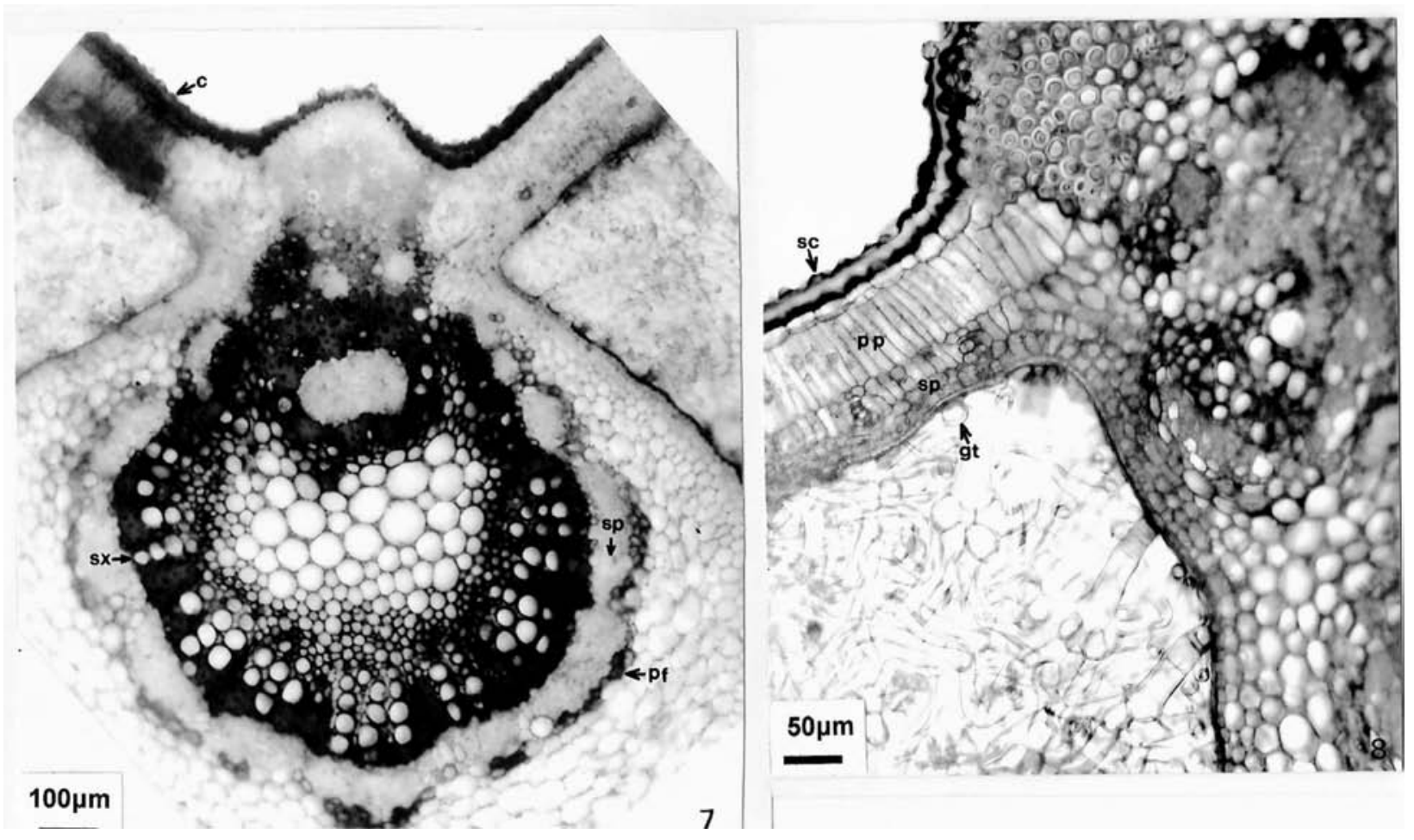

Figuras 7 e 8. Aspectos anatômicos de Zeyheria montana Mart. 7. Corte transversal do limbo: nervura central (sx = xilema secundário; $\mathrm{pf}$ = fibras do floema primário; $\mathrm{sp}$ = floema secundário; $\mathrm{c}$ = cutícula). 8. Corte transversal do limbo: mesofilo dorsiventral (sc = cutícula esculturada; pp = parênquima paliçádico; sp = parênquima lacunoso; gt = tricoma glandular). 

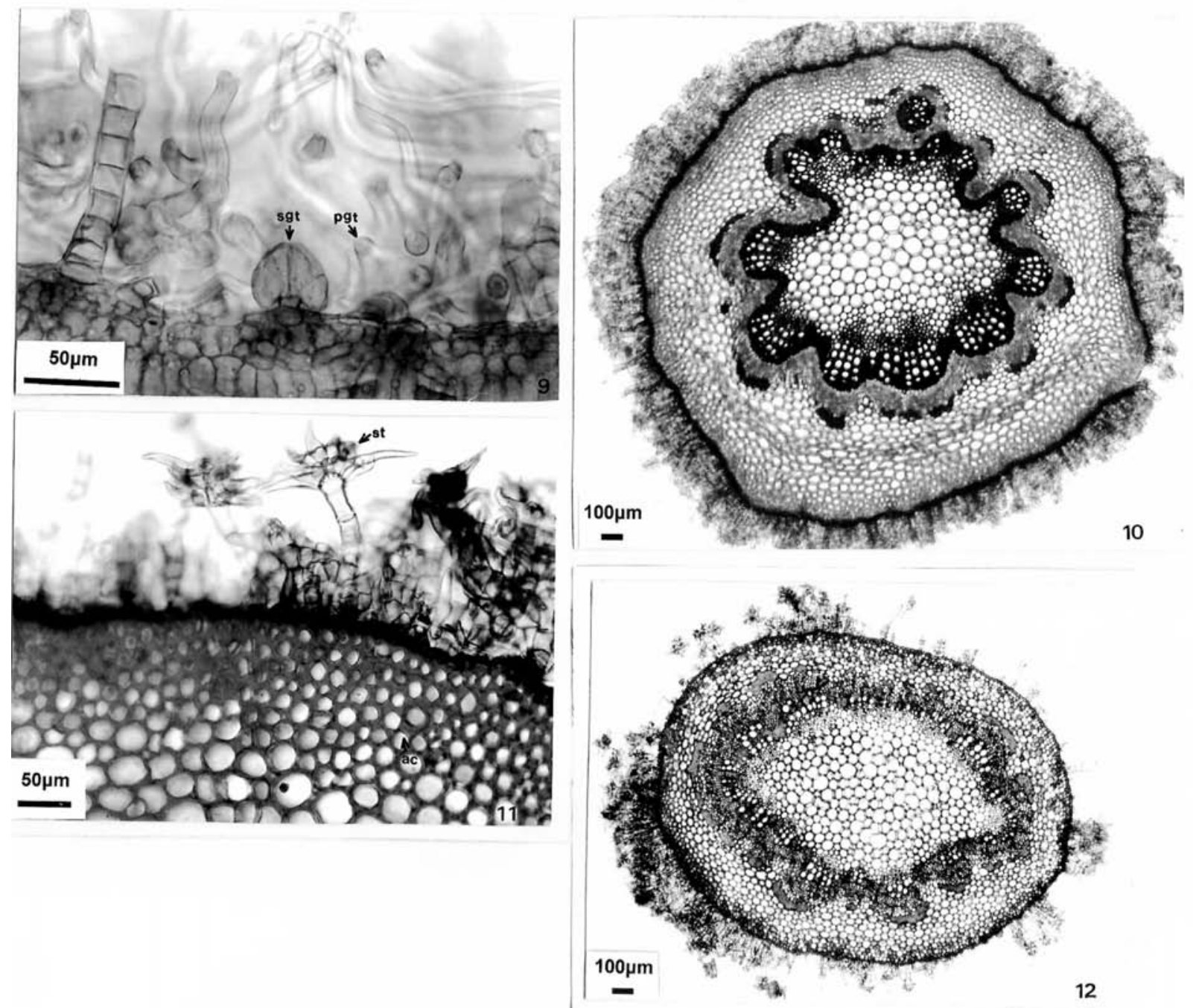

Figuras 9 a 12. Aspectos anatômicos de Zeyheria montana Mart. 9. Corte transversal do limbo (sgt = tricoma glandular séssil; pgt = tricoma glandular pedunculado). 10. Corte transversal do pecíolo (visão geral); 11 . Corte tranversal do pecíolo: detalhe (st = tricoma tector estrelado; ac = colênquima angular). 12. Corte transversal do caule (visão geral). 


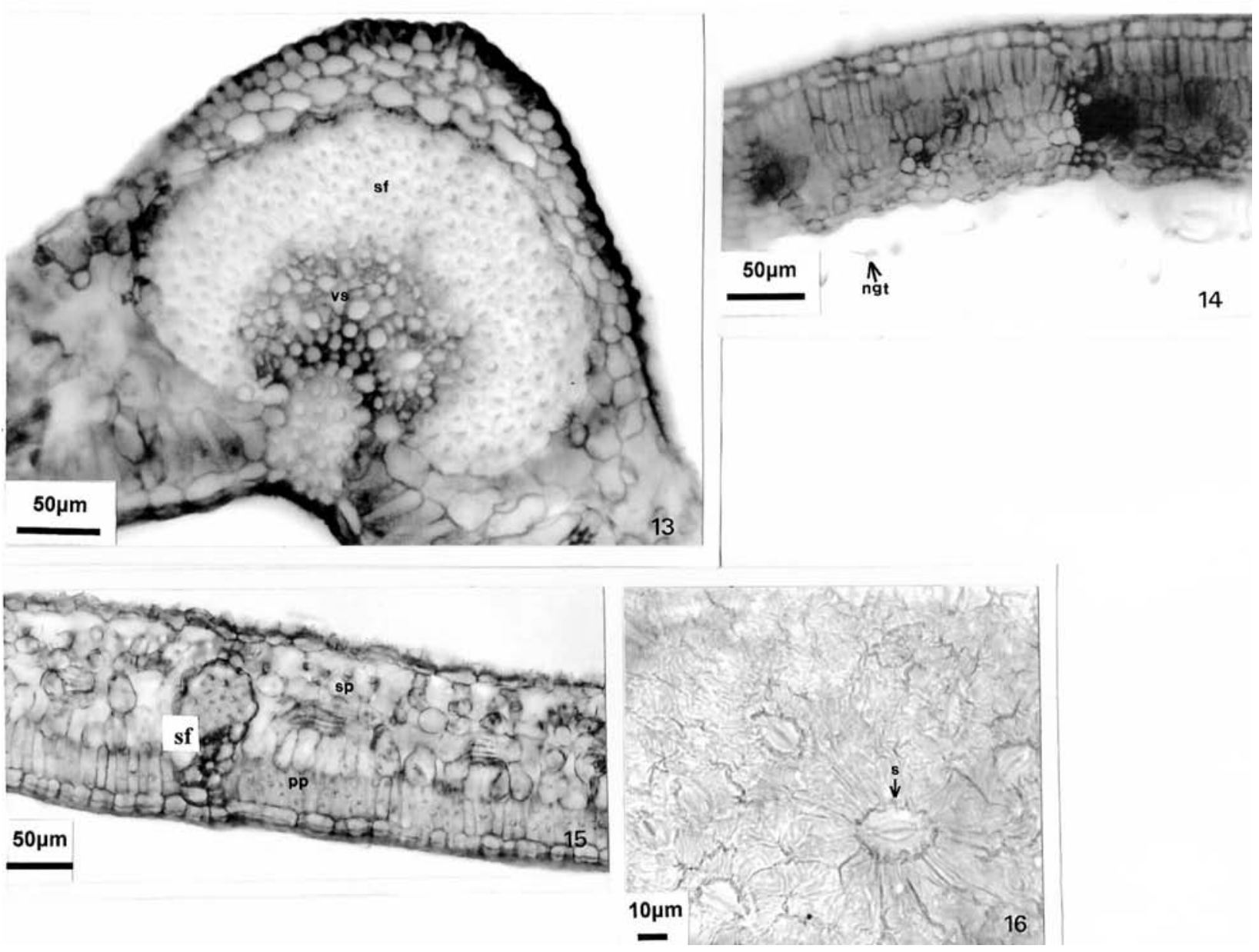

Figuras de 13 a 16. Aspectos anatômicos de Jacaranda decurrens Chamisso. 13. Corte transversal do limbo: nervura central (sf = fibras de esclerênquima; vs = feixe vascular). 14. Corte transversal do limbo (ngt = tricoma tector). 15. Corte transversal do limbo: mesofilo dorsiventral ( $\mathrm{pp}$ = parênquima paliçadico; $\mathrm{sp}$ = parênquima lacunoso; sf = fibras de esclerênquima). 16. Corte paradérmico do limbo. (s = estômato). 

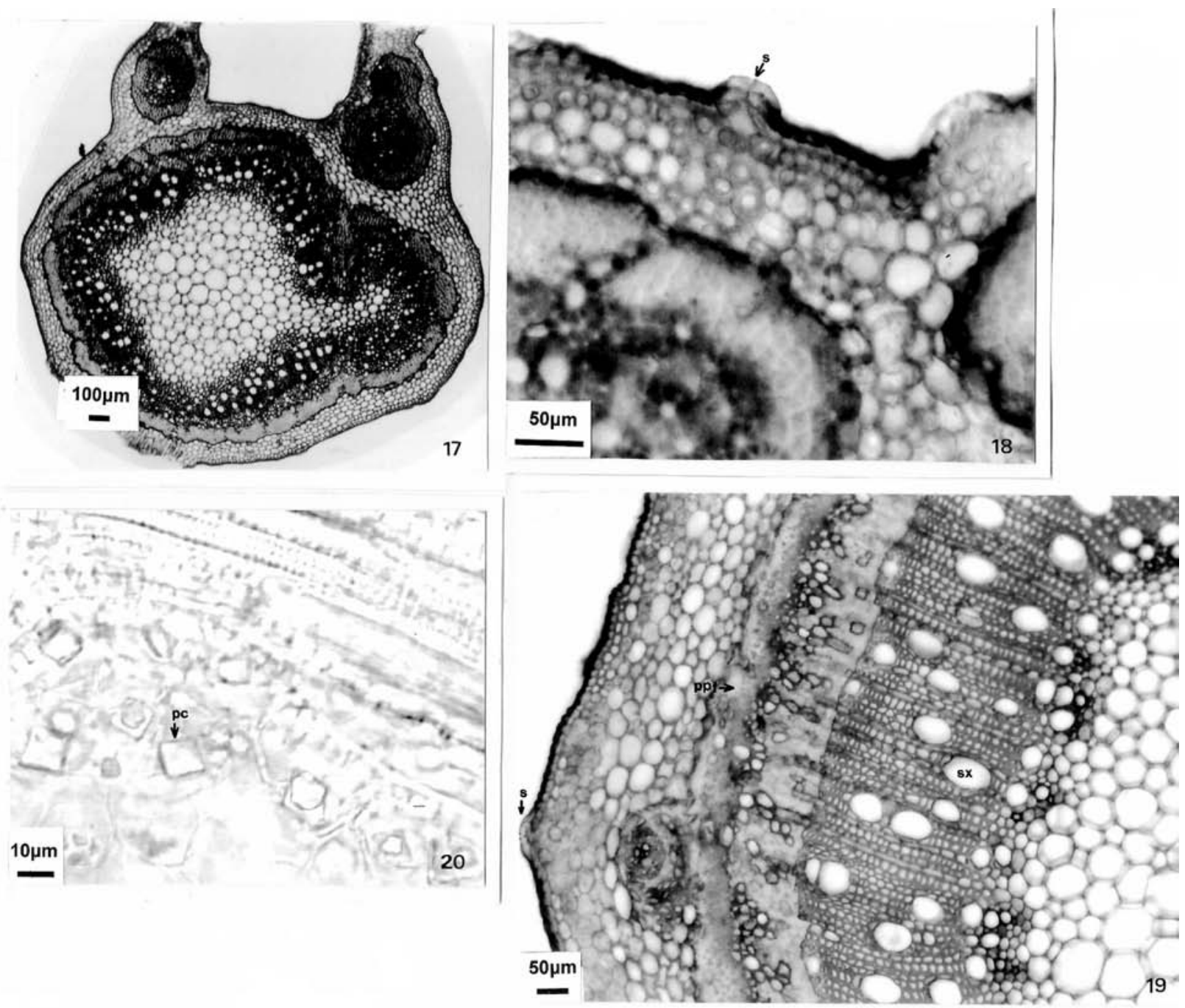

Figuras de 17 a 20. Aspectos anatômicos de Jacaranda decurrens Chamisso. 17. Corte transversal do pecíolo (visão geral). 18. Corte transversal do pecíolo: detalhe (s = estômato). 19. Corte transversal do caule (s = estômato; ppf = fibras do floema primário; $\mathrm{sx}=$ xilema secundário). 20. Corte paradérmico do limbo (pc = cristal prismático). 